\title{
'Laudato si': un nuevo paradigma ecológico"
}

\author{
Iván Fernando Mejía Correa**
}

Recibido: 15 de octubre de 2015 • Aprobado: 15 de noviembre de 2015

\section{Resumen}

En el presente artículo se presentará una descripción del problema ambiental, la denuncia y las propuestas que ha expresado la Iglesia y la posición de algunos teólogos, dando paso a destacar cómo la Encíclica "Laudato Si" se ha referido a la problemática actual del medioambiente, proponiendo con ella unos criterios de acción para restaurar la agobiada salud del planeta, y mostrando cómo la ecología emerge como un nuevo lugar teológico que promueve un nuevo paradigma a la reflexión eclesial.

Palabras Clave: creación, ecología, espiritualidad, lugar teológico, paradigma.

* Producto de la reflexión investigativa del autor. DOI: http://dx.doi.org/10.15332/ s2011-9771.2016.0001.08

* Magister en Teología y candidato a doctor en Teología por la Universidad Pontificia Bolivariana. Profesor de la Universidad Santo Tomás. Correo electróncio: frayivanmejia@ usantotomas.edu.co 


\title{
'Laudato si': A new paradigm ecological
}

\section{Abstract}

This paper presents a description of the environmental problem, reporting and the proposals expressed by the Church and the position of some theologians, ushering be presented to highlight how the Encyclical "Laudato Si "' has referred to the current problems of the environment, her criteria proposing action to restore the health of the planet harried, and showing how ecology emerges as a new theological place that promotes a new paradigm to the ecclesial reflection.

Keywords: Creation, ecology, spirituality, theological place, paradigm.

\section{'Laudato si': Un nouveau paradigme ecológico}

\begin{abstract}
Cet article présente une description du problème environnemental, les rapports et les propositions exprimées par l'Eglise et la position de certains théologiens, inaugurant être présenté pour mettre en évidence la façon dont l'Encyclique "Laudato Si "' a évoqué les problèmes actuels de l'environnement, ses critères proposant des mesures pour rétablir la santé de la planète harcelé, et montrant comment l'écologie apparaît comme un nouveau lieu théologique qui promeut un nouveau paradigme pour la réflexion ecclésiale.
\end{abstract}

Mots-clés: Création, écologie, spiritualité, lieu théologique, paradigme. 


\section{Introducción}

El papa Francisco acaba de promulgar una encíclica destinada a defender el medio ambiente, ya que:

a la continua aceleración de los cambios de la humanidad y del planeta se une hoy la intensificación de ritmos de vida y de trabajo, en eso que algunos llaman 'rapidación'. Si bien el cambio es parte de la dinámica de los sistemas complejos, la velocidad que las acciones humanas le imponen hoy contrasta con la natural lentitud de la evolución biológica (LS, 18).

Estos cambios tan vertiginosos han llevado al papa a reflexionar sobre el ecosistema, pero desde una perspectiva teologal, porque se ha dado cuenta de que el ecosistema también se ve afectado por las responsabilidades de los hombres. Es decir, toda decisión del hombre de una u otra forma afecta a la vida en todos sus niveles.

Los problemas ecológicos no son sino la repercusión negativa de las acciones de los hombres y, por obvias razones, de las naciones y estados que con sus decisiones están afectando profundamente el equilibrio sistémico del planeta.

Por eso, en el presente artículo se mostrarán los antecedentes de los problemas ecológicos y las denuncias, pero también las propuestas que presentan el Magisterio y algunos teólogos respecto de la degradación ambiental. También se mostrará cómo la encíclica es una respuesta a esta problemática, donde el papa expone ciertos tópicos que ayudan a resolver estos escollos.

De otra parte, se observa cómo la ecología adquiere un estatuto de lugar teológico, porque ya la teología debe asumir ciertos tópicos que están cobijados en los aspectos ecológicos y conducen a una ampliación de la Teología de la Creación, planteando así un nuevo paradigma ecológico que tiene en cuenta la relación Dios, hombre y cosmos -'cosmoteándrico' lo denominaba- (Panikkar, 1994). Esta tendencia responde al problema ecológico en que se evidencia en el constante rompimiento de la relación armoniosa que debe existir entre Dios, el hombre y el cosmos.

Por consiguiente, el presente artículo quiere mostrar la necesidad de este equilibrio que ya se insinúa en la encíclica del papa y sus positivas repercusiones en la Naturaleza.

Es así como la encíclica del papa Francisco se convierte en una carta de navegación donde se dan los criterios para un mejor desarrollo sostenible, y por 
obvias razones se presentan argumentos teológicos que buscan concientizar sobre la necesidad de volver a establecer la relación que debe existir entre Dios y el hombre y de éste con el cosmos. La encíclica, además, aporta nuevas intuiciones para desarrollar algunos aspectos de la mencionada Teología de la Creación, que reclama ser resaltada y abre caminos novedosos para nuevas propuestas teológicas, haciendo con esto eco a la renovación teológica que se desprende del Concilio Ecuménico Vaticano II, cuyo cincuentenario estamos recordando.

\section{Antecedentes}

Para nadie es un secreto que desde hace varios años venimos asistiendo a la destrucción del medio ambiente y, por ende, de la raza humana. En palabras de Fredy Parra Carrasco:

Hoy en todo el mundo y en nuestro propio país, crece la conciencia en torno a la crisis ecológica. Ya no es posible desconocer que vivimos una relación problemática con el medioambiente: contaminación atmosférica y destrucción de la capa de ozono, contaminación de las aguas; empobrecimiento del campo y explotación abusiva del subsuelo; peligros provenientes de residuos de todo tipo, incluidos los radiactivos; envenenamiento de los alimentos; derroche de energía y materias primas, etc. (Parra, 2011) $)^{1}$.

De otra parte, el Magisterio eclesial no ha sido ajeno a la problemática del medioambiente. Efectivamente, ya la Conferencia episcopal de Aparecida hacía un reclamo:

En las decisiones sobre las riquezas de la biodiversidad y de la Naturaleza, las poblaciones tradicionales han sido prácticamente excluidas. La Naturaleza ha sido y continúa siendo agredida. La tierra fue depredada. Las aguas están siendo tratadas como si fueran una mercancía negociable por las empresas, además de haber sido transformadas en un bien disputado por las grandes potencias (DA, 84).

1 Fredy Parra Carrasco, Esperanza en la Historia: Idea cristiana del tiempo. Santiago de Chile : Ediciones Universidad Alberto Hurtado, 2011, 78. 
Pero es pertinente recordar que ya en las Conferencia episcopales de Puebla y Santo Domingo empezaba a emerger la conciencia ecológica y va adquiriendo cuerpo en la Iglesia Latinoamericana debido al deterioro progresivo que va suscitándose en esta región (Vergara, 2005)².

Por la misma época de la Conferencia de Puebla, el papa Juan Pablo II se pronunciaba. "Ya en su primera encíclica 'Redemptor Hominis' (1979), Karol Wojtyla había llamado la atención sobre la amenaza de contaminación del ambiente natural (8). En un mundo que está dilapidando a ritmo acelerado los recursos materiales y energéticos, y comprometiendo el ambiente ecológico (16)" (Vergara, 2005) ${ }^{3}$.

El mismo papa afirmaba: "El desarrollo de la técnica no controlada en un plan a nivel universal lleva muchas veces consigo la amenaza del ambiente natural y transforma al hombre, constituido dueño y custodio inteligente y noble de la Naturaleza en un explotador y destructor sin reparo (15)" (Vergara, 2005)4. Juan Pablo II "expresa así un fenómeno que constituye un signo mayor de nuestros tiempos: la conciencia creciente del daño que hemos causado a nuestro entorno natural, acompañado de la esperanza de reparar las heridas de la madre Naturaleza" (Vergara, 2005)

También el papa Benedicto XVI abordó el tema ecológico, afirmando:

El tema del desarrollo está también muy unido hoy a los deberes que nacen de la relación del hombre con el ambiente natural. Es necesario un cambio efectivo de mentalidad que nos lleve a adoptar nuevos estilos de vida [...] Cualquier menoscabo de la solidaridad y del civismo produce daños ambientales, así como la degradación ambiental; a su vez, provoca insatisfacción en las relaciones sociales (CV, 48, 51).

En el pontificado de Francisco se observa que la problemática ecológica será un itinerario que tendrá cabida en su agenda. Por tanto, para el teólogo Cardenal Walter Kasper una de sus prioridades es "el reto de la pobreza en el mundo

2 Cf. Raúl Vergara Doxroud; Exequiel Rivas Gutiérrez; Dina Martínez; Leonidas Ortiz Losada. Manual de doctrina de la Iglesia. Bogotá : CELAM, 2005, pp. 352-366.

3 Ibíd., p. 317.

4 Ídem.

$5 \quad$ Ibíd., p. 318. 
actual" (Kasper, 2015) . Según él, una de las temáticas profundas de Francisco es la pobreza en el mundo, causada en gran parte por el sistema económico en que vive el hombre actual.

Esto -como es sabido- también ha afectado a la ecología. Las grandes multinacionales en gran medida han sido causantes de la problemática ecológica. Por lo cual, el mismo Francisco manifiesta:

La crisis financiera que atravesamos nos hace olvidar que en su origen aflora una profunda crisis antropológica: ¡la negación de la primacía del ser humano! Hemos creado nuevos ídolos [...] La crisis mundial, que afecta a las finanzas y a la economía, pone de manifiesto sus desequilibrios y, sobre todo, la grave carencia de su orientación antropológica que reduce al ser humano a una sola de sus necesidades: el consumo (EG, 55).

Los problemas económicos tienen repercusión en el medioambiente. Es decir, existe una interconexión entre los aspectos antropológicos, los temas económicos y ecológicos, todo esto agudizado por el fenómeno de la globalización. En últimas, los problemas económicos y ecológicos son netamente problemas antropológicos.

Al respecto, afirma Salvador Valadez Fuentes:

“La globalización ha acelerado la destrucción de la Naturaleza, ocasionando una crisis generalizada con relación a la vida y sus ecosistemas, debido a la explotación irracional de los recursos naturales y a la creciente contaminación del planeta; la destrucción acelerada del medio ambiente y de la biodiversidad ha causado efectos verdaderamente alarmantes" (Valdez, 2005) ${ }^{7}$.

También es preciso resaltar los comentarios que hacen los teólogos Jurgen Moltmann y Leonardo Boff en un libro que escriben a cuatro manos: “¿Hay esperanza para la creación amenazada?" En esta obra los autores manifiestan que "la crisis ecológica es un ejemplo de esa crisis total. Por eso no es algo que se resuelva tan solo técnicamente, sino que exige también un cambio de postura existencial,

6 Walter Kasper. El papa Francisco: Revolución de la ternura y el amor. Raíces teológicas y perspectivas pastorales. Maliaño, Sal Terrae, 2015, pp. 109-120.

7 Salvador Valadez Fuentes. Globalización y Solidaridad: una aproximación teológica-pastoral desde América Latina. México D.F. : Universidad Pontificia de México, 2005, p. 83. 
de estilo de vida, de valores fundamentales y de convicciones" (Moltmann y Boff, 2015) ${ }^{8}$.

Estos autores y otros coinciden con la posición del Magisterio de la Iglesia al afirmar que la problemática ecológica es en el fondo una problemática antropológica, es decir, el hombre es el que ha tergiversado el papel del mismo hombre, porque en su actuar ha sido el que rompe la relación amistosa que debe existir por parte de éste con la Creación.

Estas posiciones se pueden sintetizar cuando Aparecida asevera que "la mejor forma de respetar la Naturaleza es promover una ecología humana abierta a la trascendencia que, respetando la persona y la familia, los ambientes y las ciudades, siga la indicación paulina de recapitular todas las cosas en Cristo y de alabar con Él al Padre (Cf. 1 Co 3, 21-23 / DA, 126).

\section{La encíclica "Laudato si””}

Como es sabido, el papa Francisco ha tenido la preocupación ecológica en el lapso de 2 años que ha durado su pontificado. De hecho, antes de su encíclica "Laudato $S i$ " ya había realizado algunos pronunciamientos de la problemática de la ecología. En una audiencia general, en la plaza de San Pedro (5 de junio de 2013) el papa comentaba:

Cuando hablamos de medioambiente, de la Creación, mi pensamiento se dirige a las primeras páginas de La Biblia, al libro del Génesis, donde se afirma que Dios puso al hombre y a la mujer en la tierra para que la cultivaran y la custodiaran (Cf. 2, 15). Y me surgen las preguntas: ¿qué quiere decir cultivar y custodiar la tierra? ¿Estamos verdaderamente cultivando y custodiando la creación? ¿O bien la estamos explotando y descuidando?" (Francisco, 2016)9.

Pero, además Francisco no plantea solo preguntas sobre cómo es nuestro comportamiento con la Creación, sino que nos invita y exhorta a mantener una relación de amistad con ella cuando afirma: “Cultivar y custodiar la Creación es

8 Jurgen Moltmann; Leonardo Boff. ¿Hay esperanza para la creación amenazada? Maliaño, Sal Terrae, 2015, p. 84 .

9 Papa Francisco. Los sacramentos y los dones del Espíritu: Las catequesis del papa. Madrid: Ciudad Nueva, 2014, p. 87. 
una indicación de Dios dada no sólo al inicio de la historia, sino a cada uno de nosotros; es parte de su proyecto; quiere decir hacer crecer el mundo con responsabilidad, transformarlo para que sea un jardín, un lugar habitable para todos" (Francisco, 2016) ${ }^{10}$.

Cabe destacar que en su Exhortación apostólica 'Evangelii Gaudium', Francisco se pronuncia sobre aspectos como la economía de exclusión (Cf. 53-54), la idolatría del dinero (EG, 55-56), la inequidad que genera la violencia (EG, 59-60), que directamente repercuten en el medioambiente. Esto significa que la problemática ecológica y los desastres que se desprenden de ésta o la provocan, tienen cabida en el pensamiento de Francisco: son estas ideas las que han preparado el terreno para su nueva encíclica.

Es así como en la encíclica "Laudato Si", Francisco expone todo su pensamiento sobre la relación que debiera existir entre el hombre y el entorno ecológico. De otra parte, es la primera vez que un papa le dedica exclusivamente una encíclica a los problemas ecológicos.

La encíclica está dividida en seis partes con una introducción. En la introducción Francisco alude al "Cántico de las criaturas" de san Francisco de Asís. El papa muestra que "en este hermoso cántico nos recordaba el santo que nuestra casa común es también como una hermana, con la cual compartimos la existencia, y como una madre bella que nos acoge entre sus brazos" (LS, 1). En ese mismo preámbulo, Francisco muestra cómo sus predecesores -desde Pablo VI hasta Benedicto XVI- han abordado el problema ecológico.

También el papa muestra cómo la figura de san Francisco de Asís sigue siendo emblemática, y por ello afirma: “Creo que Francisco es el ejemplo por excelencia del cuidado de lo que es débil y de una ecología integral, vivida con alegría y autenticidad" (LS, 10).

De otra parte, el papa en esta inducción ecológica advierte que "el desafío urgente de proteger nuestra casa común incluye la preocupación de unir a toda la familia humana en la búsqueda de un desarrollo sostenible e integral, pues sabemos que las cosas deben cambiar" (LS, 13). Por último, él ofrece el derrotero de su plan de trabajo consignado en la encíclica, en el cual señala los aspectos que va a tratar en el 'corpus' del documento.

En efecto, el primer capítulo está dividido en siete partes (LS, 17-61). El papa nos presenta una descripción de la problemática actual y cómo ésta afecta el medio ambiente; aborda temas como la contaminación y el cambio climático (Cf. LS,

10 Ibíd., pp. 87-88.

\section{Universidad Santo Tomás, Facultad de Teología}


20-22), la cuestión del agua (Cf. LS, 27-31), la pérdida de la biodiversidad (Cf. LS, 3242), el deterioro de la calidad de la vida humana y la degradación Social (Cf. LS, 43-47), la inequidad planetaria (Cf. LS, 48-52), la debilidad de las reacciones (Cf. LS, 53-59) y la diversidad de opiniones (Cf. LS, 60-61).

El papa Francisco presenta una descripción detallada de la problemática actual; se nota cómo al pontífice los problemas ecológicos lo interpelan, porque estos hacen visible no solo el problema ecológico, sino el problema antropológico que se vive en la actualidad. Plantea también una denuncia a los sistemas económicos y políticos que en muchas ocasiones son cómplices del mundo contemporáneo. El papa afirma: “Llama la atención la debilidad de la reacción política internacional. El sometimiento de la política ante la tecnología y las finanzas se muestra en el fracaso de las Cumbres Mundiales sobre medio ambiente" (LS, 54).

Con estas afirmaciones Francisco manifiesta que la problemática ecológica es un problema que por un lado incumbe a todo el mundo: pobres y ricos; pero también muestra que los estados y sus políticas son insuficientes para abordar la compleja problemática.

En el segundo capítulo el papa presenta los criterios que se desprenden desde la perspectiva evangélica. Es así que divide este capítulo en siete partes donde nos presenta los siguientes tópicos: La luz que ofrece la fe (Cf. LS, 63-64), la sabiduría de los relatos bíblicos (Cf. LS, 65-75), el Misterio del Universo (Cf. LS, 76-83), el mensaje de cada criatura en la armonía de todo lo creado (Cf. LS, 84-88), una comunión universal (Cf. LS, 89-92), el destino común de los bienes (Cf. LS, 93-95), y la mirada de Jesús (Cf. LS, 96-100).

Es interesante cómo Francisco -desde la fe- quiere dar criterios para recuperar la Creación. Por una parte, muestra cómo el designio del Creador es que todos vivamos en armonía. Efectivamente, cuando acogemos la Revelación se observa que el deseo de Dios es que los hombres entran en la lógica del amor, del servicio, pero para esto estamos llamados a establecer las relaciones entre Dios, los hombres y la Creación.

Además, el pontífice expone: “Todo está relacionado, y todos los seres humanos estamos juntos como hermanos y hermanas en una maravillosa peregrinación, entrelazados por el amor que Dios tiene a cada una de sus criaturas y que nos une también, con tierno cariño, al hermano sol, a la hermana luna, al hermano río y a la Madre Tierra" (LS 92).

De otra parte, a nosotros los cristianos se nos muestra cómo la mirada de Jesús debe ser incorporada y re-creada en nuestra relación con el entorno. Cristo mismo debe ser el paradigma del cristiano también a la hora de relacionarnos 
con la Naturaleza. Es interesante cuando Francisco dice: “En los diálogos con sus discípulos, Jesús los invitaba a reconocer la relación paterna que Dios mantiene con todas las criaturas, y les recordaba con una conmovedora ternura cómo cada una de ellas es importante a sus ojos" (LS, 96).

De este modo, el creyente está invitado a acoger en su corazón los sentimientos del Padre y, por ende, de Jesús. Porque es en la práctica de estas actitudes donde se empieza a fraguar el Reino de los Cielos y, por consecuencia, la restauración de la Creación. De hecho, en la medida en que los cristianos vivamos estos sentimientos y actuemos con la lógica del Padre, estaremos viviendo su voluntad; y la voluntad de Dios es que todos se salven y en esa medida que la Creación entera se restaure.

El capítulo tercero se divide en tres a partes. Aquí se muestra que en el fondo del corazón del hombre se ha gestado la crisis ecológica. Es así que Francisco en su primer apartado nos habla de la tecnología: Creatividad y poder (Cf. LS, 102105); en segundo lugar, Globalización del paradigma tecnocrático (Cf. LS, 106-114); $\mathrm{y}$, por último, la crisis y las consecuencias del antropocentrismo moderno (Cf. LS, 115121). También en este apartado se habla de el relativismo práctico (Cf. LS, 122-123), necesidad de preservar el trabajo (Cf. LS, 124-129) e innovación biológica a partir de la investigación (Cf. LS, 130-136).

Conviene resaltar cómo el papa afirma que "el ser humano no es plenamente autónomo. Su libertad se enferma cuando se entrega a las fuerzas ciegas del inconsciente, de las necesidades inmediatas, del egoísmo y la violencia" (LS, 105). Con esto Francisco está afirmando que la crisis ecológica se produce cuando el hombre se absolutiza en la manera de administrar los bienes y se deja llevar por sus caprichos, sin tener en cuenta sus limitaciones.

En el cuarto capítulo el papa propende por una ecología integral (Cf. LS, 137), desglosando para ello este apartado en cinco puntos. En el primero se nos habla de la Ecología Ambiental, Económica y Social (Cf. LS, 138-142); el segundo apartado alude a la Ecología Cultural (Cf. LS, 143-146), el tercero a la Ecología de a vida cotidiana (Cf. LS, 147-155); el cuarto al Principio del Bien Común (Cf. LS, 156-158); y, por último, se explaya en la Justicia entre las generaciones (Cf. LS, 159-162).

Asimismo, urge destacar que Francisco llama la atención y afirma que la ecología no es algo accidental, sino que permea todas las instancias de la vida; por ello insiste que debe impregnar todas las dimensiones del hombre. Es también importante que el papa insta a asumir el principio tomista del 'Bien Común', criterio o pilar fundamental de la Enseñanza Social de la Iglesia, que todo el 
Magisterio en términos de equidad social siempre ha tenido en cuenta, a la hora de vivir en un mundo más justo.

También vuelve a la palestra el tema de la justicia, categoría de vital importancia en la Revelación, que también permea toda la mentalidad bíblica, pero trasciende a otros ámbitos de la vida humana. La justicia sigue siendo una directriz a tener en cuenta. Francisco es consciente de ello y por eso es que insiste en la necesidad de vivir la justicia en un orden individual y colectivo.

En el quinto capítulo se muestran algunas líneas de orientación y acción (Cf. LS, 163). El papa desglosa este capítulo en cinco apartados, a saber: Diálogo sobre el Medioambiente en la política internacional (Cf. LS, 164-165), Diálogo hacia nuevas políticas nacionales y locales (Cf. LS, 176-181), Diálogo y transparencia en los procesos decisionales (Cf. LS,182-188), politica y economía en diálogo para la plenitud humana (Cf. LS, 189-198), y por último, las Religiones en el diálogo con las ciencias (Cf. LS, 199-201).

Como se observa en el quinto capítulo, la palabra clave es el diálogo. Por ello afirma Francisco:

He intentado analizar la situación actual de la humanidad [...] Si bien esa contemplación de la realidad en sí misma ya nos indica la necesidad de un cambio de rumbo y nos sugiere algunas acciones, intentemos ahora delinear grandes caminos de diálogo que nos ayuden a salir de la espiral de autodestrucción en la que nos estamos sumergiendo (LS, 163).

Por último, Francisco presenta el sexto capítulo intitulado Educación y Espiritualidad ecológica (Cf. LS, 202), que a su vez se divide en nueve apartados, a saber: Apostar por otro estilo de vida (Cf. LS, 203-208), Educación para la Alianza entre la Humanidad y el Ambiente (Cf. LS, 209-215), Conversión ecológica (Cf. LS, 216-221), Gozo y Paz (Cf. LS, 222-227), Amor civil y político (Cf. LS, 228-232), Signos sacramentales y descanso celebrativo (Cf. LS, 233-237), La Trinidad y la relación entre las criaturas (Cf. LS, 238-240), Reina de todo lo creado (Cf. LS, 241-242), y por último, 'Más allá del sol' (Cf. LS, 243-246).

La espiritualidad es toda una manera de existir, y en esa medida Francisco está invitando a vivir de una manera nueva que ayude a reconstruir la armonía que se ha perdido. Apela a la educación, es decir, a tomar conciencia de que cada uno es responsable del medioambiente, pero para esto es necesario tener una conversión, sabiendo que implica un cambio en la mentalidad y se traduce en 
renunciar a modelos de vida antinaturales que son contraproducentes contra la vida del planeta.

También nos invita a entronizar el descanso pero desde una perspectiva celebrativa. Todo no puede ser trabajo y producción, el hombre y la Creación necesitan descansar. De otra parte, el papa insta a ver cómo el modelo trinitario nos invita a entrar en comunión.

Y, por último, a tener a la Virgen María como modelo porque Ella ha sabido vivir. Es decir, su existencia le deja al hombre contemporáneo una gran enseñanza. En segundo lugar, el papa invita a estar preparados porque "al final nos encontraremos cara a cara frente a la infinita belleza de Dios (Cf. I Co 13, 12), y podremos re-leer con feliz admiración el misterio del universo, que participará con nosotros de la plenitud sin fin" (LS, 243).

\section{La ecología como lugar teológico}

La teología es una ciencia dinámica que cada día está llamada a explicitar el sentido del contenido de la Revelación. Es decir: el trabajo del teólogo consiste en observar los 'signos de los tiempos' para profundizar cada vez más la verdad revelada.

En consecuencia, el teólogo debe explorar otros posibles lugares teológicos, a saber:-como dice Antonio Morales-: “La teología puede, por lo tanto, ocuparse de cualquier realidad terrenal, siempre que lo haga: a) para detectar y explicar su sentido último a la luz del Evangelio; y b) para determinar su repercusión espiritual y moral en el hombre". (Morales, 2008) ${ }^{11}$

Eso significa que los teólogos se pueden ocupar de la ecología y de sus problemas. Es así como el papa Francisco, después de describir la problemática ambiental, ha aportado unos criterios tomados de la Revelación para iluminar cuál debe ser la relación que debe existir entre el hombre, la Creación y, en últimas, el Creador. En esto el papa da ejemplo de cómo los teólogos deben abordar las nuevas realidades, tales como la ecología, la cultura, la política, etc.

Ahora bien, cuando analizamos las sagradas Escrituras encontramos:

Los relatos de la Creación en el libro del Génesis contienen, en su lenguaje simbólico y narrativo, profundas enseñanzas sobre la existencia

11 José Morales. Introducción a la teología. Navarra: Eunsa, 2008, p. 53.

\section{Universidad Santo Tomás, Facultad de Teología}


humana y su realidad histórica. Estas narraciones sugieren que la existencia humana se basa en tres relaciones fundamentales estrechamente conectadas: la relación con Dios, con el prójimo y con la tierra (LS, 66).

Esto significa que el entorno -y en este caso las criaturas que rodean a los hombres- también están en relación con éste. Si tienen relación con el hombre, se constituyen en un lugar teológico, ateniéndose a lo que explica Antonio Morales (2008).

Además de esto, observamos cómo la Teología de la Creación también al hacer su reflexión ha tenido en cuenta las demás criaturas; por ello "lo que importa, por encima de todo, es acercarse al resto de la Creación con actitud reverente y ver la Naturaleza desde una perspectiva sacramental, porque Dios está en ella, y Cristo lo estuvo" (Bradley, 1993) ${ }^{12}$.

Desde luego, cuando contemplamos la Creación nos damos cuenta de que "la fe en la Creación no nos dice en qué consiste el sentido del mundo, sino sólo que el mundo tiene, de hecho, sentido: todas las vicisitudes del ser en devenir son realización libre -y expuesta al riesgo de la libertad- de la originaria idea creadora de la que recibe el ser" (Ratzinger, 2001) ${ }^{13}$.

En la Creación podemos contemplar el deseo del Creador. En aquélla se manifiesta la belleza, la bondad y la verdad. Por eso, destruir la Creación es acabar con la belleza, terminar con la bondad de la misma creación y desdecir de la verdad de Dios que se manifiesta en las creaturas.

Francisco -al escribir la encíclica "Laudato $\mathrm{Si}^{\prime}$-, afirma:

Siempre es posible volver a desarrollar la capacidad de salir de sí hacia el otro. Sin ella no se reconoce a las demás criaturas en su propio valor, no interesa cuidar algo para los demás, no hay capacidad de ponerse límites para evitar el sufrimiento o el deterioro de lo que nos rodea. La actitud básica de auto-trascenderse, rompiendo la conciencia aislada y la autorreferencialidad, es la raíz que hace posible todo cuidado de los demás y del medioambiente, y que hace brotar la reacción moral de considerar el impacto que provoca cada acción y cada decisión personal fuera de uno mismo (LS, 208).

12 Ian Bradley. Dios es verde: Cristianismo y medio ambiente. Maliaño, Sal Terrae, 1993, p. 151.

13 Joseph Ratzinger (papa Benedicto XVI). Fe y Ciencia: Un diálogo necesario (Maliaño, Sal Terrae, 2011, p. 128. 
De ahí que la ecología es una cuestión que incumbe a todas las personas, y con mayor razón a los cristianos. Los creyentes están invitados a mantener una relación cordial con la Creación. Esto lleva a afirmar con tajantemente que la Ecología se convierte actualmente en un lugar teológico por excelencia.

Hoy es imposible hacer teología sin tener en cuenta el entorno ambiental, a sabiendas de que la crisis ecológica es producto de una crisis de los hombres; por ello Francisco llama la atención en que "cuando no se reconoce en la realidad misma el valor de un pobre, de un embrión humano, de una persona con discapacidad -por poner sólo algunos ejemplos- difícilmente se escucharán los gritos de la misma Naturaleza" (LS, 117).

Y en otro apartado se afirma: "Si la crisis ecológica es una eclosión o una manifestación externa de la crisis ética, cultural y espiritual de la Modernidad, no podemos pretender sanar nuestra relación con la Naturaleza y el ambiente sin sanar todas las relaciones básicas del ser humano" (LS, 119).

Por esto, todo lo que ocurre en el medioambiente está reflejando el comportamiento del hombre mismo. Toda la destrucción que se ha presentado en los últimos años evidencia que la humanidad está enferma en sus corazones.

Cuando se ha perdido la experiencia de Dios, también se ha deteriorado el respeto por la Creación y, por ende, por el medioambiente. Cuando Dios se apaga en la conciencia de los hombres, las criaturas dejan de ser tales para volverse objetos de mercancía, y pierden así su belleza y gratuidad. Según eso, los temas ambientales deben empezar a ser parte de los tratados de teología. No significa que la Teología de la Creación pasará a reducirse a biología; de lo que se trata es de que la ecología se debe constituir en un lugar teológico por excelencia, máxime en nuestra época tan amenazada.

El medio ambiente -como lo hemos observado- muestra cómo ha sido la relación del hombre con la Creación, pero también muestra que la relación con el Creador está muy afectada. Por eso Francisco invita a recordar "el modelo de san Francisco de Asís, para proponer una sana relación con lo creado como una dimensión de la conversión íntegra de la persona. Esto implica también reconocer los propios errores, pecados, vicios o negligencias, y arrepentirse de corazón, cambiar desde adentro" (LS, 218). 


\section{Un nuevo y urgente paradigma ecológico}

Palabras como contaminación, cambio climático, bien común, biodiversidad, son conceptos que ya hacen parte ya del acervo cultural del hombre contemporáneo y que constituyen un nuevo paradigma.

Este referente también afecta a la teología, porque ésta ha tenido que integrar en su discurso nuevas cuestiones, nuevas problemáticas, nuevos estadios de reflexión. Al saber que los paradigmas "expresan, por tanto, una constelación general, un patrón básico, un esquema fundamental, un modelo global, según el cual la teología se percibe a sí misma, a las personas, la sociedad, el mundo y, sobre todo, su relación con Dios" (Dos Anjos, 1999) ${ }^{14}$.

A todas luces, estas ideas, conceptos y maneras de vivir han afectado el panorama teológico. La teología está en mora de reflexionar sobre estas nuevas realidades: el cambio climático, la deforestación, la destrucción de la capa de ozono, porque esto en el fondo está destruyendo al mismo hombre y, por otro lado, devela la radical crisis ética de la humanidad.

En consecuencia, la teología actual debe asumir nuevos lenguajes y realidades diferentes, y por ende metodologías renovadas. Eso significa que el teólogo debe captar nuevos lugares teológicos para desarrollar su reflexión. Es así que estos fenómenos ecológicos empiezan a configurar nuevos paradigmas que -por obvias razones- afectan a la teología.

Sabemos de estas realidades y fenómenos que afectan en este caso a la teología, cuando:

se da un cambio de paradigma cuando hay una irrupción de muchas señales innovadoras, muchos factores y elementos de los que el paradigma en curso ya no da cuenta. Esas señales aparecen, a veces, aisladamente como precursoras, revelan ciertas arritmias en el funcionamiento del paradigma vigente. Grupos críticos captan una tendencia general percibida por las grandes masas. Se procesa un cambio fundamental, duradero, ampliamente aceptado en la percepción de las cosas $(\mathrm{LS}, 38)^{15}$.

14 Marcio Fabro Dos Anjos (Ed.) Teología y nuevos paradigmas. Sao Paulo : Mensajero, 1999, p. 37.

15 Ibíd., p. 38. 
Hoy se percibe un nuevo paradigma, es decir una serie de ideas que han revolucionado la política, la economía, la cultura y en este caso la ecología y la teología. Irrumpen nuevos conceptos como globalización, neoliberalismo, 'Nueva era', tribus urbanas, etc., que también han cambiado la manera de ver y pensar el mundo y, por ello, la teología.

Otro tanto ha ocurrido con la ecología, donde se habla de productos transgénicos, derechos de animales, ecoética, desarrollo sostenible, etc., que van introduciendo unas concepciones nuevas que muestran que la realidad ambiental ha cambiado bruscamente.

En consecuencia, la Iglesia no ha sido ajena a este cambio, pues ya los últimos papas han venido hablando de los problemas ecológicos. Las conferencias latinoamericanas poco a poco han introducido el tema de la ecología.

Las facultades de teología, en esta misma línea, empiezan a indagar estos nuevos aspectos. Se realizan seminarios, se intenta reflexionar sobre la problemática ecológica, se construyen programas de teología donde la cátedra de 'Ecoteología' ya es tenida en cuenta. Es decir, el mundo de la reflexión teológica empieza a aceptar estos nuevos paradigmas.

Ahora bien, Francisco mediante su encíclica lo que pretende es explicitar que los problemas ecológicos tocan al hombre y, por ende, son susceptibles de estudio por parte de la teología. Es así que ya en la Iglesia se empieza a observar que es necesario apelar a un nuevo paradigma ecológico. De hecho, este papa apuesta por ello, al mostrar que este nuevo paradigma ecológico se construye cuando hay un cambio de políticas. Aparecen nuevas alternativas en el campo económico y una nueva pedagogía empieza a reflexionarse.

Todo esto, en el fondo, pide una revisión de la mentalidad que se tiene frente a la manera de vivir. Para esto es preciso estar dispuesto a dialogar y buscar nuevas alternativas; a entrar en diálogo con las religiones que son un factor fuerte de unidad o desunión. $\mathrm{Y}$ a estar dispuesto a cambiar el estilo de vida; a cuidar, en suma, la Creación, porque es la 'Casa común' ('oikoumene') o lugar donde vivimos.

Es así como Francisco en su encíclica está postulando un nuevo estilo de vida. Por eso afirma:

Muchas cosas tienen que reorientar su rumbo, pero ante todo la humanidad necesita cambiar. Hace falta la conciencia de un origen común, de una pertenencia mutua y de un futuro compartido por todos. Esta conciencia básica permitiría el desarrollo de nuevas convicciones, actitudes y formas de vida. Se destaca así un gran desafío cultural, 
espiritual y educativo que supondrá largos procesos de regeneración (LS, 202).

Francisco entonces aboga por un cambio de paradigma ecológico. De hecho, su carta plantea algunos principios para tratar de restaurar el medio ambiente. Fiel al Magisterio de la Iglesia y de sus antecesores, el papa exhorta al cuidado de la Creación y a restablecer la relación perdida entre Dios y sus criaturas, y de éstas con el medioambiente.

\section{Conclusiones}

1. Se observa cómo persiste una serie de fenómenos que muestran que la Creación sufre un creciente deterioro que está socavando las bases mismas de la existencia de la vida en el planeta.

2. La Iglesia no es ajena a esta problemática, pues ha venido insistiendo a través de sus documentos en la necesidad de cambiar las políticas y el sistema económico actual por un modelo más equitativo y sostenible.

3. La Encíclica "Laudato Si" es la primera encíclica que está destinada a mostrar la problemática actual sufrida por el medio ambiente, pero también a mostrar soluciones alternativas inspiradas en la Revelación cristiana.

4. Indiscutiblemente, la ecología se convierte en lugar teológico, porque sus realidades afectan al hombre. Pero también develan la crisis ética y la pérdida del sentido del Absoluto. En últimas, los fenómenos como el cambio climático y la deforestación, expresan el rompimiento del hombre con Dios y, como consecuencia nefasta, con la Creación.

5. El papa Francisco apela a un nuevo paradigma ecológico, que restructure la forma de vivir, cambiando modelos y políticas destructivas por otras que busquen el equilibrio y que propendan por una Nueva Humanidad. 


\section{Referencias}

Bradley, I. (1993). Dios es verde: Cristianismo y medio ambiente. Maliaño: Sal Terrae.

Conclusiones. (2007). V Conferencia General del Episcopado Latinoamericano y del Caribe. Brasil: Aparecida.

Dos Anjos, M. F. (1999). Teología y nuevos paradigmas. Sao Paulo: Mensajero.

Francisco, papa (2013). Exhortación apostólica 'Evangelii Gaudium'.

(2015). Encíclica 'Laudato Si'. En: http://w2.vatican.va/content/francesco/ es/encyclicals/documents/papa-francesco_20150524_enciclica-laudato-si.html. Recuperado: 12/08/2015.

(2014). Los sacramentos y los dones del Espíritu: Las catequesis del papa. Madrid: Ciudad Nueva.

Kasper, Walter, Cardenal (2015). El papa Francisco: Revolución de la ternura y el amor. Raíces teológicas y perspectivas pastorales. Maliaño: Sal Terrae.

Moltmann, J. \& Boff, L. (2015). ¿Hay esperanza para la Creación amenazada? Maliaño: Sal Terrae.

Morales, J. (2008). Introducción a la teología. Navarra : Eunsa.

Parra, F. (2011). Esperanza en la Historia: Idea cristiana del tiempo. Santiago de Chile: Ediciones Universidad Alberto Hurtado.

Ratzinger, J. (papa Benedicto XVI) (2011). Fe y Ciencia: Un diálogo necesario. Maliaño: Sal Terrae.

Valadez, S. (2005). Globalización y Solidaridad: una aproximación teológica-pastoral desde América Latina. México D.F.: Universidad Pontificia de México.

Vergara, R., Rivas, E., Martínez, D. \& Ortiz, L. (2005). Manual de doctrina social de la Iglesia. Bogotá: CELAM. 